\title{
The effectiveness, risks and improvement of laparoscopic pancreaticoduodenectomy during the learning curve: a propensity score-matched analysis
}

\author{
Long Huang ${ }^{1,2 \#}$, Yifeng Tian ${ }^{1,2 \#}$, Jiayi $\mathrm{Wu}^{1,2 \#}$, Maolin Yan $^{1,2}$, Funan Qiu ${ }^{1,2}$, Songqiang Zhou ${ }^{1,2}$, Yannan Bai ${ }^{1,2}$, \\ Zhide Lai ${ }^{1,2}$, Yaodong Wang ${ }^{1,2}$, Shi Chen ${ }^{1,2}$ \\ ${ }^{1}$ Department of Hepatobiliary Surgery, Fujian Provincial Hospital, Fuzhou, China; ${ }^{2}$ Fujian Medical University, Fuzhou, China \\ Contributions: (I) Conception and design: S Chen; Y Tian; (II) Administrative support: S Chen; (III) Provision of study materials or patients: All \\ authors; (IV) Collection and assembly of data: All authors; (V) Data analysis and interpretation: L Huang, Y Tian, J Wu; (VI) Manuscript writing: All \\ authors; (VII) Final approval of manuscript: All authors. \\ \#These authors contributed equally to this work as co-first authors. \\ Correspondence to: Yifeng Tian, MD; Shi Chen, MD. Department of Hepatobiliary Surgery, Fujian Provincial Hospital, Fujian Medical University, \\ 134 East Street, Fuzhou 350001, China. Email: yifengtian123@126.com; wawljwalj@163.com.
}

Background: Propensity score-matched analyses comparing the safety and efficacy of laparoscopic pancreaticoduodenectomy (LPD) to open pancreaticoduodenectomy (OPD) that consider the effect of the learning curve for LPD are lacking. We use Propensity score-matched to compare the safety and efficacy of LPD during the learning curve to OPD.

Methods: The medical records of 296 consecutive patients who had undergone LPD or OPD between September 2016 and August 2019 at Fujian Provincial Hospital were retrospectively reviewed. Patients treated with LPD were matched 1:1 to those treated with OPD. Calculation of propensity scores considered age, gender, body mass index (BMI), tumor location, pathology, incidence of obstructive jaundice, incidence of biliary drainage, pancreatic texture, pancreatic duct diameter, previous abdominal surgery, comorbidities, and case distribution of the surgical team.

Results: After propensity score matching, 196 patients were divided into two groups: 98 patients in the LPD group and 98 patients in the OPD group. LPD performed during the learning curve was associated with a longer median operative time (OT) (432 vs. $328 \mathrm{~min}, \mathrm{P}<0.001$ ), a higher incidence of major surgeryassociated complications $(32.7 \%$ vs. $14.3 \%, \mathrm{P}=0.002)$, a higher incidence of clinically relevant pancreatic fistula (27.6\% vs. $13.3 \%, \mathrm{P}=0.013)$, and prolonged LOS (21.06 d vs. $16.94 \mathrm{~d}, \mathrm{P}=0.033)$, but lower median intraoperative blood loss (200 vs. $300 \mathrm{~mL}, \mathrm{P}<0.001)$ compared to OPD. Mean OT and LOS were significantly shorter in the late phase of the learning curve for $\operatorname{LPD}(\mathrm{P}<0.001)$, and were similar to that for OPD. Age $>60$ years and a non-dilated MPD were significant predictors of clinically relevant pancreatic fistula, major surgery-associated complications, prolonged LOS and postoperative mortality at 90 days (all $\mathrm{P}<0.05)$.

Conclusions: OT, incidence of major surgery-associated complications, and LOS were significantly increased in patients that underwent LPD, but were significantly improved during the learning curve. Elderly patients and patients with a non-dialated MPD should not be treated with LPD performed by inexperienced surgeons.

Keywords: Laparoscopic pancreaticoduodenectomy (LPD); learning curve; safety profile; open pancreaticoduodenectomy (OPD); efficacy

Submitted Jan 12, 2020. Accepted for publication Jun 30, 2020.

doi: 10.21037 /gs-20-98

View this article at: http://dx.doi.org/10.21037/gs-20-98 


\section{Introduction}

Globally, laparoscopic pancreaticoduodenectomy (LPD) is gaining widespread acceptance among pancreatic surgeons (1). However, LPD is technically challenging, requiring a long learning curve and a proficient surgeon $(2,3)$.

Several reports have compared the efficacy and safety of LPD to open pancreaticoduodenectomy (OPD), suggesting that the feasibility and safety of LPD remain controversial (4). Two studies showed no significant differences in the postoperative complication rate and overall survival in patients treated with LPD compared to OPD, but intraoperative blood loss, length of hospital stay (LOS), and delayed gastric emptying were lower in patients treated with $\operatorname{LPD}(5,6)$. A propensity scorematched analysis that identified patients through the pancreas-targeted American College of Surgeons National Surgical Quality Improvement Program demonstrated that the operative time (OT) was longer and the rate of postoperative readmission was higher, but average LOS was shorter and the postoperative infection rate was lower, in patients treated with LPD compared to OPD; there were no significant differences in the overall complication rate, mortality, incidence of pancreatic fistula, or delayed gastric emptying (7). A pan-European propensity score-matched analysis found a higher incidence of postoperative clinically relevant pancreatic fistula in patients treated with LPD compared to OPD (8).

Some studies have considered the effect of the learning curve for LPD on postoperative outcomes (2,5,7-12). A study of patients identified from the US National Cancer Database indicated that the 30-day mortality rate after LPD was related to the volume of the surgery center, whereby the mortality rate was higher at lower-volume centers (<10 LPDs annually) (10). A multicenter study in China showed that OT, estimated intraoperative blood loss, and mortality in patients treated with LPD were associated with the surgeon's experience. The risk of surgical failure was reduced by higher hospital, department, and surgeon volume, and increased surgeon experience (12).

Although learning curves have been described, it is currently unknown how much extra risk is associated with the learning curve. To the authors' knowledge, no propensity score-matched analyses comparing the safety and efficacy of LPD to OPD have considered the effect of the learning curve for LPD (7,10,12-15). Therefore, the objective of this study was to compare the safety and efficacy of LPD during the learning curve to OPD using propensity score matching, and to compare the perioperative outcomes of LPD and evaluate improvement across different phases of the learning curve. Findings could inform patient selection during the learning curve for LPD and improve surgical safety. We present the following article in accordance with the STROBE reporting checklist (available at http://dx.doi. org/10.21037/gs-20-98).

\section{Methods}

\section{Study design}

This retrospective, cross-sectional study was performed at the Fujian Provincial Hospital, which is affiliated to Fujian Medical University, between September 2016 and August 2019. The study was conducted in accordance with the Declaration of Helsinki (as revised in 2013), and the protocol was approved by the institutional review board at Fujian provincial hospital (ID: K2019-04-002). And informed consent was taken from all the patients.

Inclusion criteria were (I) $\geq 18$ years old; (II) a diagnosis of a resectable malignant or borderline malignant carcinoma of the pancreatic head (stage I and II pancreatic cancer), distal common bile duct, or periampullary region according to the National Comprehensive Cancer Network (NCCN) Guidelines; and 3) treated with OPD or LPD.

Exclusion criteria were: (I) tumor size $>10 \mathrm{~cm}$ that had invaded adjacent organs and major vessels; (II) involvement of the superior mesenteric vein (SMV) or portal vein (PV) ( $>3 \mathrm{~cm}$ in length) detected on preoperative thin-slice $(3 \mathrm{~mm})$ computed tomography (CT) and CT portal venography; (III) treated with neoadjuvant chemoradiation therapy; (IV) serious cardiopulmonary or hepatorenal insufficiency; or (V) extensive intraperitoneal or extraperitoneal metastases.

\section{Surgical procedures}

In accordance with institutional practice guidelines, all patients underwent routine hematology, biochemistry, and oncology testing. Abdominal thin-slice $(3 \mathrm{~mm})$ CT was used to identify the size and location of the lesions. All surgical procedures were performed by an assigned surgical team led by a board-certified attending general surgeon experienced in both open and laparoscopic surgery.

Surgeries involved a standard pancreaticoduodenectomy procedure, as previously described (16). Open surgery was performed using a roof-shaped incision under the arcus costarum, and laparoscopic surgery was performed using 5 
surgical trocars. All patients underwent a two-layered endto-side, duct-to-mucosa pancreaticojejunostomy.

\section{Postoperative care}

On postoperative Day 1 or 2, the nasogastric tube was removed, and patients were frequently fed small amounts of a low-fat soft, solid diet, if well tolerated. Plasma glucose was closely monitored, and intravenous insulin was administered for management of hyperglycemia. On postoperative Day 5 , the amylase concentration in the peritoneal drainage fluid was measured, and the drain was removed if there was no apparent pancreatic fistula.

\section{Main outcome measures}

Patients medical records were reviewed and the following variables were recorded: patient characteristics, including age, gender, body mass index (BMI), American Society of Anesthesiologists (ASA) score, and presence of comorbidities, such as diabetes mellitus, hypertension, and cardiac and pulmonary disease; operative variables, including conversion rate, OT, intraoperative blood loss, and transfusion rate; postoperative variables including incidence of pancreatic fistula and biliary fistula (17), overall morbidity, mortality, time to resume out-of-bed activities, and LOS; and pathological variables including histological classification, tumor size, number of lymph nodes resected and positive nodes, TNM stage, resection margin (the common bile duct, SMVs, PV, pancreatic neck, and uncinate process), pancreatic texture, and main pancreatic duct (MPD) diameter.

Pancreatic fistula was diagnosed in accordance with the International Study Group for Pancreatic Fistula (ISGPF) criteria (18); a Grade B/C pancreatic fistula was considered clinically relevant. Postoperative morbidities were assessed using the Clavien-Dindo classification system; ClavienDindo Grade $\geq 3$ was considered a major complication. MPD in LPD was assessed on a laparoscopic millimeter scale.

\section{Propensity score matching}

Propensity score matching was used to minimize bias caused by variables that could otherwise confound comparisons between OPD and LPD. Outcomes of the matched samples were directly compared to estimate the treatment effect.
Calculation of propensity scores considered the following covariates: age, gender, BMI, tumor location, pathology, incidence of obstructive jaundice, incidence of biliary drainage, pancreatic texture, pancreatic duct diameter, previous abdominal surgery, comorbidities, and case distribution of the surgical team. Patients treated with LPD were matched 1:1 to those treated with OPD.

\section{Statistical analysis}

Statistical analyses were conducted with SPSS 23.0 (SPSS Inc., Chicago, IL, USA). Continuous data are expressed as mean \pm standard deviation $(\mathrm{SD})$, mean \pm standard error of the mean (SEM), or median (interquartile range, IQR), and means were compared using the two independent samples Student $t$-test. Categorical data were compared using the $\chi^{2}$ test or Fisher's exact probability test. Non-normally distributed variables were evaluated with the MannWhitney $U$ test. Univariate and multivariate analysis were performed to identify risk factors for clinically relevant pancreatic fistula, major surgery-associated complications, prolonged LOS, and mortality. Results are expressed as odd ratios (OR) with corresponding $95 \%$ CIs.

The learning curve for LPD was quantitatively assessed using the cumulative sum (CUSUM) method, as previously described (12). CUSUM learning curves for OT and intraoperative blood loss were constructed, whereby CUSUM $=\sum_{i=1}^{n}(x i-u)$ and $\mathrm{Xi}$ is the OT or intraoperative blood loss for each patient, and $\mathrm{u}$ is the mean OT or intraoperative blood loss of all patients. The Spearman rank correlation coefficient ( $\rho$ ) was used to determine whether there was a significant downtrend in OT or intraoperative blood loss. A P value $<0.05$ was considered statistically significant.

\section{Results}

\section{Patients' baseline characteristics}

This study included 296 unmatched patients. Of these, 113 patients underwent LPD and 183 patients underwent OPD. After propensity score matching, 196 patients were divided into two groups: 98 patients in the LPD group and 98 patients in the OPD group. Covariates were compared between groups, before and after matching (Table 1). Before matching, there were imbalances in pancreatic texture and MPD diameter, which are risk factors for pancreatic fistula, and hypertension and hypoproteinemia. All imbalances 
Table 1 Baseline characteristics before and after propensity score matching

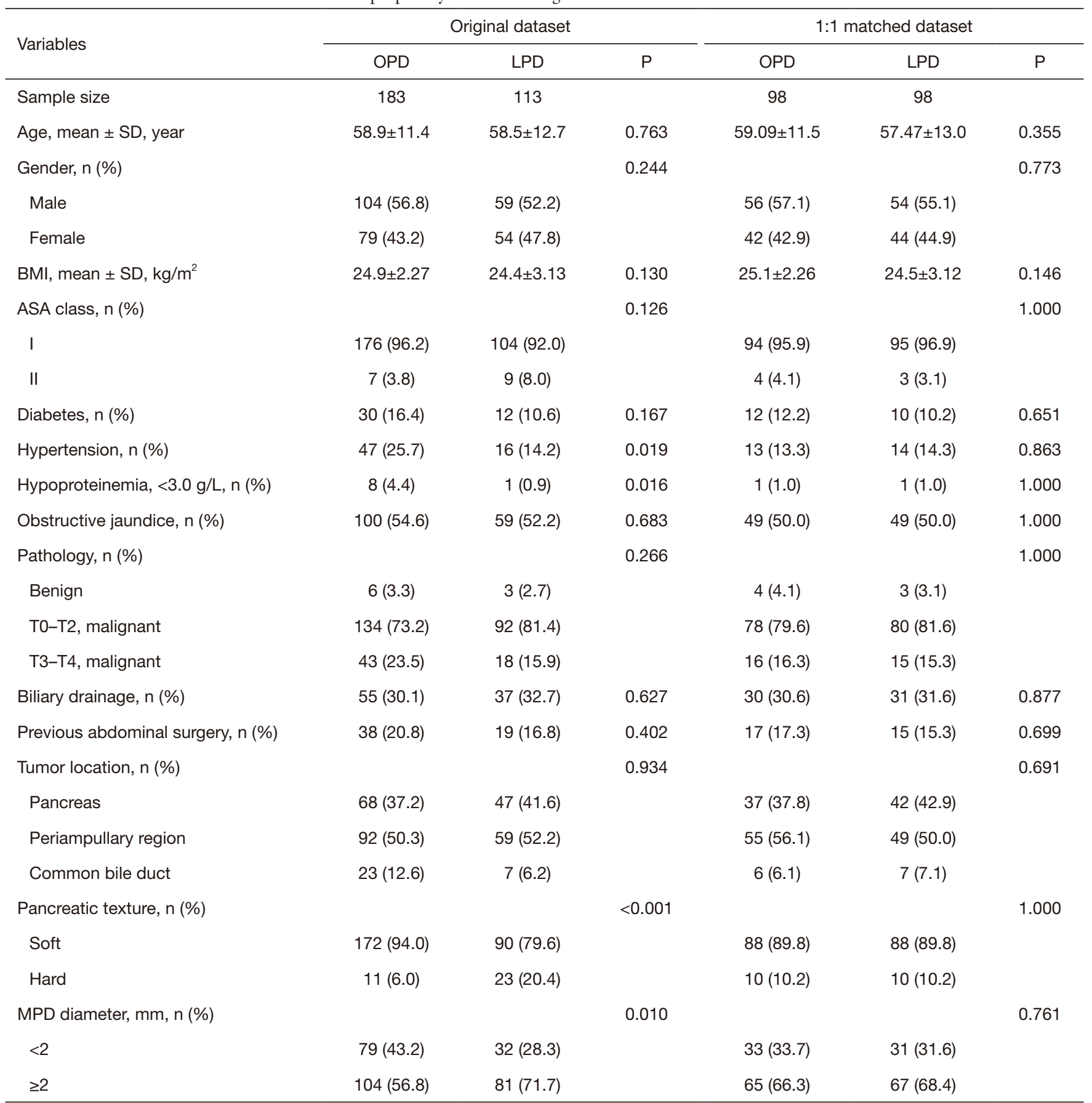

OPD, open pancreaticoduodenectomy; LPD, laparoscopic pancreaticoduodenectomy; BMI, body mass index; SD, standard deviation; ASA, American Society of Anesthesiologists. 
were alleviated by matching.

\section{Intraoperative outcomes}

Intraoperative outcomes were compared between the OPD and LPD matched groups (Table 2). Median OT was significantly longer (median: 432 vs. $328 \mathrm{~min}, \mathrm{P}<0.001$ ) but median blood loss was significantly lower (200 vs. 300 $\mathrm{mL}, \mathrm{P}<0.001)$ in patients that underwent LPD compared to those that underwent OPD. There was no significant difference in the incidence of transfusions between groups.

\section{Postoperative outcomes}

Morbidity and recovery data for the OPD and LPD matched groups are shown in (Table 2). There was no significant difference in overall morbidity or incidence of pancreatic fistula between groups. The incidence of Clavien-Dindo Grade III-IV complications (33.3\% vs. $15.8 \%, \mathrm{P}=0.03)$, clinically relevant pancreatic fistula (32.7\% vs. $14.3 \%, \mathrm{P}=0.002)$, and bleeding that required invention, including drug treatment or digital subtraction angiography $(17.3 \%$ vs. $4.1 \%, \mathrm{P}=0.005)$ was significantly higher in patients that underwent LPD compared to those that underwent OPD. However, there was no significant difference in the incidence of bleeding that required reoperation between groups, and the incidence of surgical site infection was significantly lower in patients that underwent LPD (3.1\% vs. $18.4 \%, \mathrm{P}=0.001)$. There was no significant difference in 90-day mortality between the two groups.

Mean times to resume out-of-bed activities, bowel movements, and oral intake of a low-fat soft, solid diet were significantly shorter in patients that underwent LPD compared to those that underwent OPD (all $\mathrm{P}<0.05$ ). LOS was significantly longer (21.06 vs. 16.94 days, $\mathrm{P}=0.033$ ) and the incidence of prolonged LOS ( $>30 \mathrm{~d}$ ) was significantly higher in patients that underwent LPD (31.6\% vs. 10.5\%, $\mathrm{P}=0.006)$. Mean LOS was significantly shorter for patients with no or mild surgery-associated complications $(\mathrm{P}<0.001)$ but significantly longer for patients with major surgeryassociated complications $(\mathrm{P}<0.001)$ in patients that underwent LPD compared to those that underwent OPD (Table 3).

\section{Pathology}

There were no significant differences in pathological variables in all patients included in the OPD and LPD matched groups or among patients with pancreatic adenocarcinoma (Table 2).

\section{Multivariate logistic regression analysis}

Univariate and multivariate analysis identifying risk factors for clinically relevant pancreatic fistula, major surgeryassociated complications, prolonged LOS, and mortality are shown in Table 4. Age $>60$ years, LPD, and a nondilated MPD were significant predictors of clinically relevant pancreatic fistula and major surgery-associated complications. Age $>60$ years and a non-dilated MPD were significant predictors of postoperative mortality at 90 days $($ all $\mathrm{P}<0.05)$. On univariate analysis, age $>60$ years, LPD, clinically relevant pancreatic fistula, major surgeryassociated complications, and a non-dilated MPD were associated with prolonged LOS; however, multivariate analysis identified major surgery-associated complications and a non-dilated MPD as two significant predictor of prolonged LOS $(\mathrm{P}<0.05)$.

\section{Learning curve analysis}

CUSUM-CT analyses for OT and blood loss are shown in Figure 1 and Figure 2. For LPD, there were significant improvements after 34 cases and 65 cases (Figure 1). There were significant dips in the learning curve for OT (Figure $2 A, \mathrm{P}<0.001$ ) and intraoperative blood loss $(\mathrm{P}<0.001$; Figure $2 B)$. The learning curve for OT appeared to reach the lowest point, suggesting that our surgical teams achieved competence in performing LPD.

Intraoperative and postoperative outcomes were evaluated in patients across three phases of the learning curve for LPD that were delineated by the 34th and 65 th case treated. There were no significant differences in the baseline characteristics or pathology in patients treated during the early, middle, or late phases of the learning curve (Table 5). The last 48 patients (late phase) had significantly shorter OT and LOS, lower blood loss, and lower incidence of morbidity, major complications, pancreatic fistula and conversion to laparotomy (all $\mathrm{P}<0.05$ ), compared to patients treated in the early and middle phases.

Patients treated with LPD and OPD in the late phase of the learning curve were compared using propensity score matching (Table 6). After matching, there were 43 patients in each group. There were no differences in OT, LOS, and incidence of morbidity, major complications, or clinical 
Table 2 Intra-and postoperative 90-day outcomes and pathology

\begin{tabular}{|c|c|c|c|}
\hline Variables & OPD & LPD & $P$ \\
\hline Operative blood loss, median (IQR), mL & $300[200-500]$ & $200[100-400]$ & $<0.001$ \\
\hline OT, median (IQR), min & 328 [284-391] & $432[330-493]$ & $<0.001$ \\
\hline Blood transfusion, $\mathrm{n}(\%)$ & $10(10.2)$ & $9(9.2)$ & 1.000 \\
\hline Clavien-Dindo 3-5 (major), n (\%) & $14(14.3)$ & $32(32.7)$ & 0.002 \\
\hline Pancreatic fistula, n (\%) & $27(27.6)$ & $40(40.8)$ & 0.050 \\
\hline BL & $14(14.3)$ & $13(13.3)$ & 0.836 \\
\hline $\mathrm{B} / \mathrm{C}$ & $13(13.3)$ & $27(27.6)$ & 0.013 \\
\hline Bleeding requiring reoperation, $\mathrm{n}(\%)$ & $3(3.1)$ & $6(6.1)$ & 0.497 \\
\hline Abdominal infection, n (\%) & $11(11.1)$ & $20(20.4)$ & 0.073 \\
\hline Pulmonary infection, n (\%) & $16(16.3)$ & $10(10.2)$ & 0.206 \\
\hline Wound infection, $\mathrm{n}(\%)$ & $18(18.4)$ & $3(3.1)$ & 0.001 \\
\hline Delayed gastric emptying, n (\%) & $8(8.2)$ & $10(10.2)$ & 0.621 \\
\hline Oral intake, mean $\pm \mathrm{SD}, \mathrm{d}$ & $4.01 \pm 0.93$ & $2.98 \pm 0.83$ & $<0.001$ \\
\hline Bowel movement, mean $\pm S D, d$ & $4.49 \pm 1.43$ & $2.98 \pm 1.27$ & $<0.001$ \\
\hline Off-bed activities, mean $\pm S D, d$ & $4.63 \pm 2.05$ & $3.04 \pm 1.48$ & $<0.001$ \\
\hline Distal CBD adenocarcinoma & $7(7.1)$ & $9(9.2)$ & 0.602 \\
\hline periampullary adenocarcinoma & $38(38.8)$ & $45(45.9)$ & 0.312 \\
\hline IPMN & $2(2.0)$ & $6(6.1)$ & 0.297 \\
\hline SPT & $2(2.0)$ & $8(8.2)$ & 0.100 \\
\hline Others & $17(17.3)$ & $10(10.2)$ & 0.147 \\
\hline Tumor size, $\mathrm{cm}$, mean $\pm \mathrm{SD}$ & $2.46 \pm 0.61$ & $2.56 \pm 0.59$ & 0.171 \\
\hline Lymph nodes resected, mean \pm SD & $14.96 \pm 4.22$ & $14.27 \pm 3.94$ & 0.236 \\
\hline Microscopically positive (R1) margins, n (\%) & $1(1.0)$ & $2(2.0)$ & 1.000 \\
\hline Pancreatic adenocarcinoma & $n=32$ & $\mathrm{n}=20$ & \\
\hline Tumor size, $\mathrm{cm}$, mean $\pm \mathrm{SD}$ & $2.40 \pm 0.37$ & $2.28 \pm 0.58$ & 0.385 \\
\hline Lymph nodes resected, mean $\pm \mathrm{SD}$ & $13.53 \pm 3.90$ & $12.95 \pm 3.49$ & 0.589 \\
\hline
\end{tabular}

Table 2 (continued) 
Table 2 (continued)

\begin{tabular}{|c|c|c|c|}
\hline Variables & OPD & LPD & $P$ \\
\hline Positive nodes, mean \pm SD & $2.40 \pm 1.31$ & $2.62 \pm 1.83$ & 0.705 \\
\hline \multicolumn{4}{|l|}{ T stage, n (\%) } \\
\hline $\mathrm{T} 1$ & $6(18.8)$ & $4(20.0)$ & 1.000 \\
\hline T3 & $16(50.0)$ & $6(30.0)$ & 0.156 \\
\hline LN (+), n (\%) & $19(59.4)$ & $8(40.0)$ & 0.174 \\
\hline \multicolumn{4}{|l|}{ AJCC stage, n (\%) } \\
\hline IA & $5(15.6)$ & $4(20.0)$ & 0.719 \\
\hline IIB & $19(59.4)$ & $7(35.0)$ & 0.087 \\
\hline
\end{tabular}

OPD, open pancreaticoduodenectomy; LPD, laparoscopic pancreaticoduodenectomy; OT, operative time; IQR, interquartile range; BL, biochemical fistula; SD, standard deviation; LOS, Length of hospital stay; CBD, common bile duct; IPMN, intraductal papillary mucinous neoplasm, SPT, solid pseudopapillary tumor, AJCC American Joint Committee on Cancer classification.

Table 3 LOS for patients with no or mild (Clavien-Dindo Grade I-II) or major (Clavien-Dindo Grade III-V) surgery-associated complications

\begin{tabular}{|c|c|c|c|}
\hline Variables & OPD & LPD & $\mathrm{P}$ \\
\hline Major complications (Clavien-Dindo Grade III-V), mean \pm SD, $d$ & $35.46 \pm 5.16$ & $44.87 \pm 7.21$ & $<0.001$ \\
\hline
\end{tabular}

LOS, Length of hospital stay; OPD, open pancreaticoduodenectomy; LPD, laparoscopic pancreaticoduodenectomy; SD, standard deviation.

pancreatic fistula between groups (all $\mathrm{P}>0.05$ ).

\section{Discussion}

To the author's knowledge, this is the first study to compare the safety and efficacy of LPD during the learning curve to OPD. Biases associated with patients clinical characteristics were controlled for using the propensity score-matching method. Based on the outcomes analyzed, CUSUM-CT analysis revealed that the learning curve for LPD consisted of 3 phases.

Matched analyses showed that OT, the incidence of Clavien-Dindo Grade III-IV complications, clinically relevant pancreatic fistula, bleeding that required invention, and prolonged LOS ( $>30 \mathrm{~d}$ ), and LOS for patients with major surgery-associated complications were significantly increased in patients that underwent LPD during the learning curve compared to those that underwent OPD. These data indicate that there is a risk associated with LPD during the learning curve. However, the risks that were initially associated with LPD were significantly decreased in the late phase of the learning curve. In addition, intraoperative blood loss, the incidence of surgical site infection, times to resume out-of-bed activities, bowel movements, and oral intake of a low-fat soft, solid diet, and LOS for patients with no or mild surgery-associated complications were significantly lower in patients that underwent LPD.

Previous studies have showed no increase in postoperative complication and mortality rates in patients that underwent LPD compared to OPD (7,19-21). Other reports suggest that the postoperative complication and mortality rates associated with LPD are increased in lowvolume centers where surgeons are less experienced in the 
Table 4 Univariate and multivariate analysis for complication

\begin{tabular}{|c|c|c|c|c|c|c|}
\hline Variables & \multicolumn{3}{|c|}{ Univariate } & \multicolumn{3}{|c|}{ Multivariable } \\
\hline \multicolumn{7}{|c|}{ Clinical pancreatic fistula (grade B/C) } \\
\hline Age $>60 y$ & 2.17 & $1.05,4.46$ & 0.036 & 2.83 & $1.19,6.75$ & 0.019 \\
\hline Female gender & 0.82 & $0.4,1.66$ & 0.58 & & & \\
\hline Diabetes & 0.85 & $0.27,2.67$ & 0.784 & & & \\
\hline Previous abdominal surgery & 1.97 & $0.65,5.98$ & 0.232 & & & \\
\hline LPD & 2.48 & $1.2,5.17$ & 0.015 & 3.47 & $1.38,8.71$ & 0.008 \\
\hline Blood loss $>200 \mathrm{~mL}$ & 0.5 & $0.25,1$ & 0.051 & 0.77 & $0.32,1.86$ & 0.567 \\
\hline MPD $<2 \mathrm{~mm}$ & 9.11 & $4.14,20.07$ & $<0.001$ & 11.28 & $4.71,27.06$ & $<0.001$ \\
\hline T3-T4, malignant & 0.37 & $0.11,1.29$ & 0.118 & & & \\
\hline \multicolumn{7}{|c|}{ Major complications (Clavien-Dindo Grade III-V) } \\
\hline Age $>60$ y & 3.32 & $1.62,6.81$ & 0.01 & 4.85 & $1.99,11.79$ & $<0.001$ \\
\hline Female gender & 0.87 & $0.45,1.7$ & 0.688 & & & \\
\hline $\mathrm{BMI}>25$ & 0.94 & $0.53,2.01$ & 0.939 & & & \\
\hline Diabetes & 1.25 & $0.46,3.42$ & 0.656 & & & \\
\hline Previous abdominal surgery & 2.41 & $0.79,7.27$ & 0.119 & & & \\
\hline MPD $<2 \mathrm{~mm}$ & 5.61 & $2.76,11.38$ & $<0.001$ & 8.4 & $3.53,20.01$ & $<0.001$ \\
\hline T3-T4, malignant & 0.75 & $0.29,1.96$ & 0.557 & & & \\
\hline \multicolumn{7}{|l|}{ 90-day mortality } \\
\hline Age $>60 y$ & 3.44 & $1.88,6.29$ & $<0.001$ & 3.92 & $2.02,7.64$ & $<0.001$ \\
\hline Female gender & 0.63 & $0.35,1.14$ & 0.125 & & & \\
\hline $\mathrm{BMI}>25$ & 1.01 & $0.57,1.82$ & 0.961 & & & \\
\hline Diabetes & 1.6 & $0.66,3.89$ & 0.302 & & & \\
\hline Previous abdominal surgery & 1.56 & $0.69,3.5$ & 0.283 & & & \\
\hline LPD & 1.29 & $0.73,2.29$ & 0.382 & & & \\
\hline Blood loss >200 mL & 0.79 & $0.44,1.4$ & 0.413 & & & \\
\hline Soft pancreatic texture & 1.26 & $0.48,3.3$ & 0.644 & & & \\
\hline Operative time $>300 \mathrm{~min}$ & 1.44 & $0.73,2.86$ & 0.294 & & & \\
\hline
\end{tabular}

Table 4 (continued) 
Table 4 (continued)

\begin{tabular}{|c|c|c|c|c|c|c|}
\hline Variables & \multicolumn{3}{|c|}{ Univariate } & \multicolumn{3}{|c|}{ Multivariable } \\
\hline MPD $<2$ mm & 5.09 & $2.68,9.68$ & $<0.001$ & 5.72 & $2.87,11.4$ & $<0.001$ \\
\hline T3-T4, malignant & 1.77 & $0.82,3.83$ & 0.146 & & & \\
\hline \multicolumn{7}{|l|}{ Prolonged LOS >30 d } \\
\hline Female gender & 0.76 & $0.38,1.5$ & 0.427 & & & \\
\hline $\mathrm{BMI}>25$ & 1.13 & $0.58,2.24$ & 0.717 & & & \\
\hline Diabetes & 1.02 & $0.35,2.94$ & 0.974 & & & \\
\hline Previous abdominal surgery & 2.26 & $0.75,6.83$ & 0.149 & & & \\
\hline Soft pancreatic texture & 2.82 & $0.63,12.66$ & 0.176 & & & \\
\hline Operative time $>300 \mathrm{~min}$ & 2.42 & $0.95,6.14$ & 0.063 & 1.35 & $0.39,4.67$ & 0.634 \\
\hline Major complications & 39.67 & $15.82,99.44$ & $<0.001$ & 24.22 & $7.93,73.99$ & $<0.001$ \\
\hline Clincal Pancreatic Fistula & 7.44 & $3.45,16.06$ & $<0.001$ & 0.7 & $0.21,2.38$ & 0.567 \\
\hline MPD $<2$ mm & 5.64 & $2.75,11.57$ & $<0.001$ & 4.16 & $1.42,12.14$ & 0.009 \\
\hline T3-T4, malignant & 1.01 & $0.4,2.53$ & 0.985 & & & \\
\hline
\end{tabular}

$\mathrm{Cl}$, confidence interval; OR, odds ratio; BMI, body mass index; LPD, laparoscopic pancreaticoduodenectomy; MPD, main pancreatic duct.

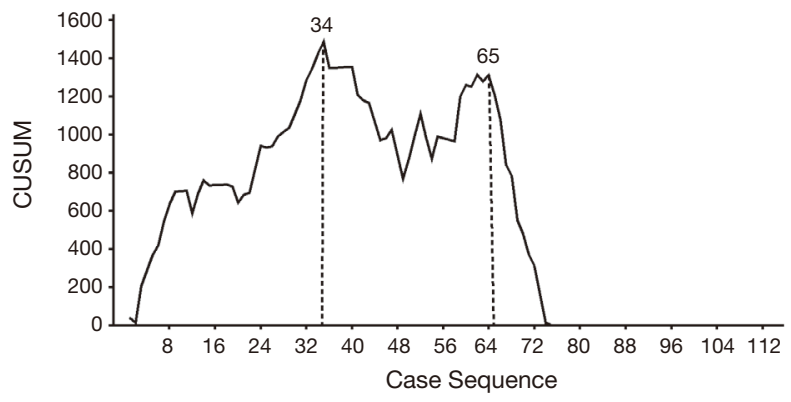

Figure 1 Cumulative sum graph for operative time.

procedure (10,22-25). A recent multicentre, patient-blinded randomized controlled trial comparing LPD with OPD (LEOPARD-2) was prematurely stopped due to the high rate of complication-related 90 -day mortality in the LPD group $(26,27)$. Importantly, none of the inclusion criteria for these aforementioned studies required surgeons to have passed the learning curve for LPD, which had obvious implications for patient outcomes.

The learning curve for LPD has been investigated in several studies. One retrospective study of LPD conducted at a high-volume centre showed decreased OT from $9.8 \mathrm{~h}$ for the first 33 patients to $6.6 \mathrm{~h}$ for the last 40 patients in 100 patients, but the learning curve analysis of this study was not using CUSUM-CT method (28). Wang et al. reported there were two peak points in their learning curve assessed by the CUSUM method, which were observed at the 11th and 31st cases; however, the sample size of this study was small (3). A retrospective multicentre study of LPD in China demonstrated the learning curve had 3 phases, with proficiency thresholds at 40 and 104 cases; however, this study lacked a comparison of efficacy between different phases, and had not compared LPD and OPD data during the same period (12). Some other studies used CUSUM analysis to find that the OT of LPD decreased with experience are similar to this study $(2,29)$. Our study had two features distinguishing it from previous reports. Firstly, we objectively determined 

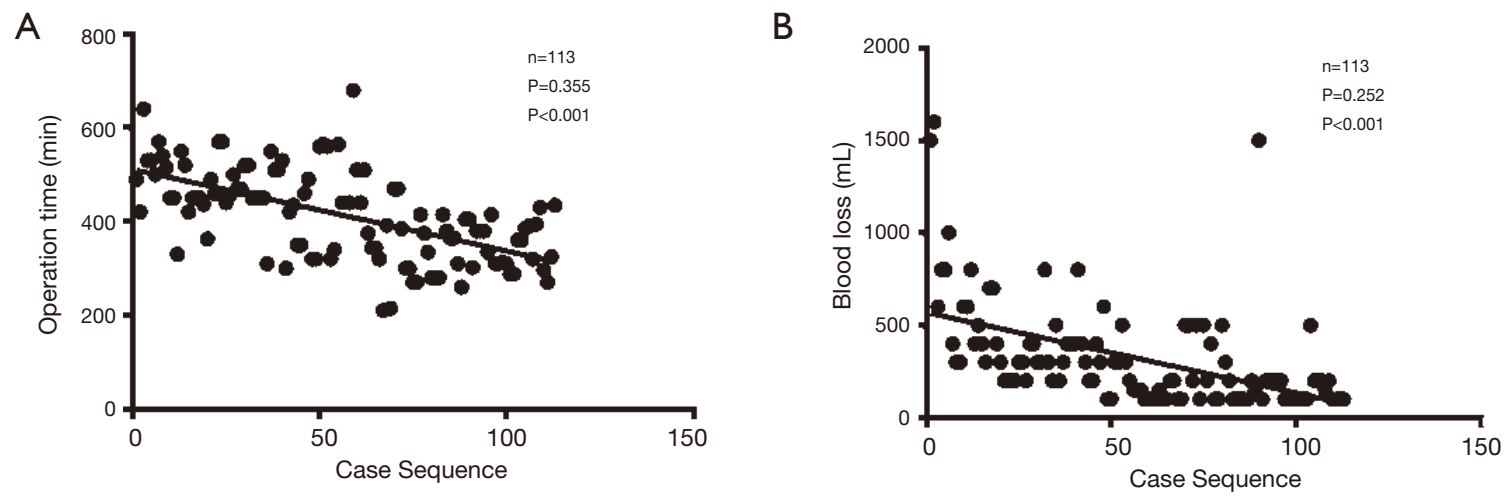

Figure 2 learning curve for OT (A) and intraoperative blood loss (B). OT, operative time.

Table 5 Baseline characteristics and intra-and postoperative 90-day outcomes of patients treated with LPD stratified by 3 phases

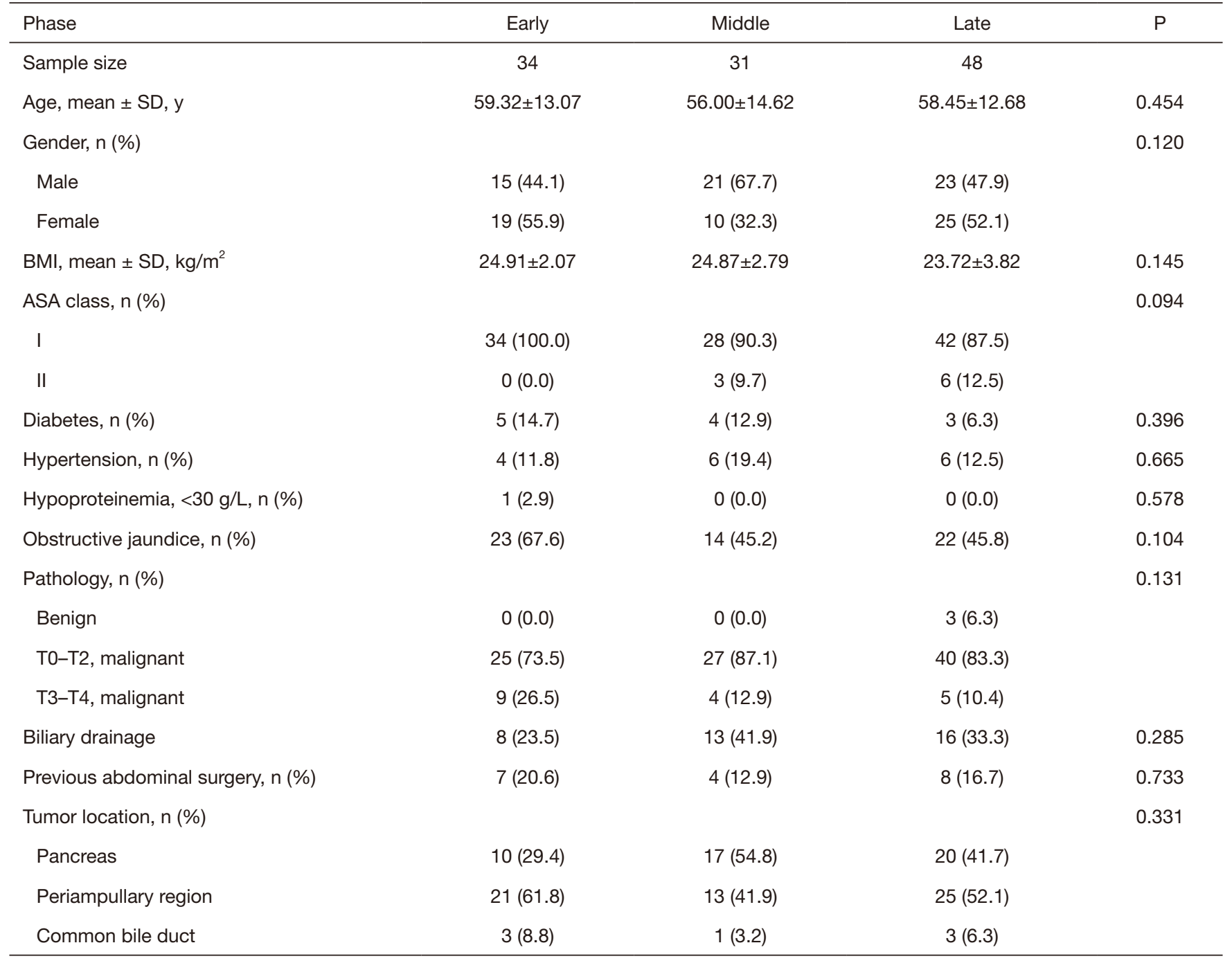

Table 5 (continued) 
Table 5 (continued)

\begin{tabular}{|c|c|c|c|c|}
\hline Phase & Early & Middle & Late & $P$ \\
\hline Soft & $28(82.4)$ & $23(74.2)$ & $39(81.3)$ & \\
\hline Hard & $6(10.5)$ & $8(25.8)$ & $9(18.8)$ & \\
\hline MPD diameter, mm, n (\%) & & & & 0.837 \\
\hline$\geq 2$ & $25(73.5)$ & $23(74.2)$ & $33(68.8)$ & \\
\hline Operative blood loss, median (IQR), mL & $350(275-600)$ & $200(100-300)^{\dagger \dagger}$ & $200(100-350)^{*}$ & $<0.001$ \\
\hline Operative time, median (IQR), min & $470(450-522)$ & $440(344-510)$ & $335(297-388)^{\star \dagger}$ & $<0.001$ \\
\hline Morbidity, n (\%) & $16(47.1)$ & $18(58.1)$ & $12(25.0)^{\star \dagger}$ & 0.009 \\
\hline $\mathrm{BL}$ & $3(8.8)$ & $7(22.6)$ & $5(10.4)$ & 0.241 \\
\hline $\mathrm{B} / \mathrm{C}$ & $13(38.2)$ & $9(29.0)$ & $6(12.5)^{\star \dagger}$ & 0.024 \\
\hline Bile leakage, n (\%) & $2(5.9)$ & $2(6.5)$ & $0(0.0)$ & 0.174 \\
\hline Pulmonary infection, n (\%) & $4(11.8)$ & $4(12.9)$ & $3(6.3)$ & 0.564 \\
\hline Wound infection, n (\%) & $1(2.9)$ & $2(6.5)$ & $1(2.1)$ & 0.692 \\
\hline Delayed gastric emptying, n (\%) & $4(11.8)$ & $4(12.9)$ & $2(4.2)$ & 0.259 \\
\hline Bleeding requiring intervention, $n(\%)$ & $9(26.5)$ & $6(19.4)$ & $2(4.2)^{\star \dagger}$ & 0.013 \\
\hline Bleeding requiring reoperation, $\mathrm{n}(\%)$ & $3(8.8)$ & $2(6.5)$ & $1(2.1)$ & 0.423 \\
\hline LOS $>30 d$ & $14(41.2)$ & $10(32.3)$ & $7(14.6)^{\star \dagger}$ & 0.023 \\
\hline 90-day mortality, n (\%) & $4(11.8)$ & $2(6.5)$ & $1(2.1)$ & 0.218 \\
\hline
\end{tabular}

${ }^{*}, \mathrm{P}<0.05$ for Later vs. Early; ${ }^{\dagger}, \mathrm{P}<0.05$ for Later vs. Middle; ${ }^{\dagger \dagger}, \mathrm{P}<0.05$ for Early vs. Middle. SD, standard deviation; MPD, main pancreatic duct; IQR, interquartile range; BL, biochemical fistula; LOS, Length of hospital stay.

improvement in intraoperative and postoperative outcomes during the learning curve for LPD by a large sample size. Findings confirmed that the learning curve for LPD had 3 phases. There was a significant decline in the OT, LOS, and incidence of postoperative complications or clinically relevant pancreatic fistula across the three phases, suggesting that improvement in surgical performance over time has a beneficial effect on patient outcomes.
Secondly, although overall effectiveness of LPD during the learning curve was not as good as OPD, the efficacy of LPD approached that of OPD in the later stages of the learning curve for LPD. Our results raise concern about the effectiveness of LPD performed by less experienced surgeons in clinical practice, but should encourage them to learn the procedure. It may be advantageous to shift the learning curve from patient treatment to preclinical 
Table 6 Intra-and postoperative 90-day outcomes of patients treated with OPD and LPD in late phase of learning curve after propensity score matching

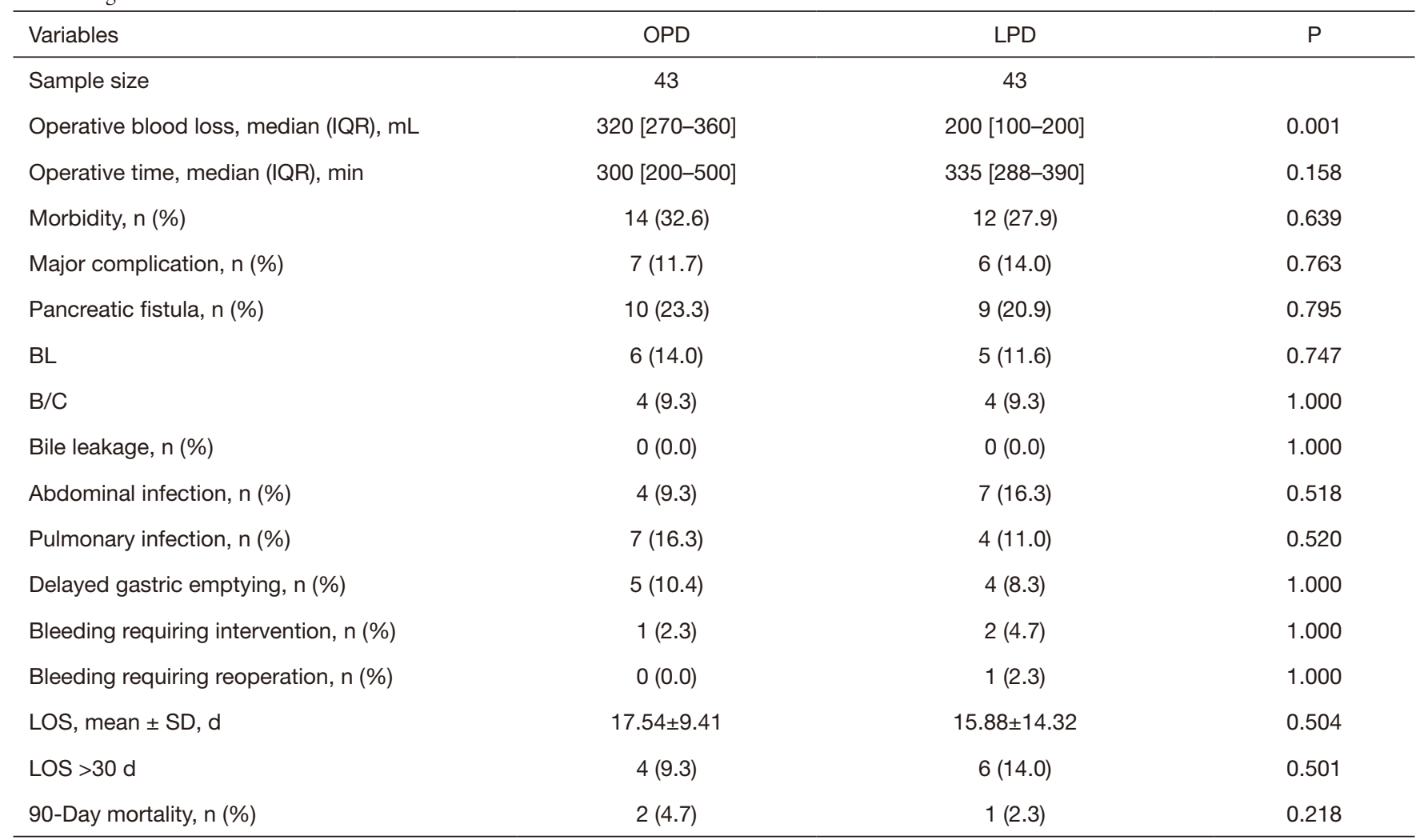

OPD, open pancreaticoduodenectomy; LPD, laparoscopic pancreaticoduodenectomy; IQR, interquartile range; BL, biochemical fistula; LOS, Length of hospital stay.

simulation training that encompasses early stage and more advanced pancreatic cancer cases (26).

Surgery-associated complications and LOS are important factors for evaluating the effectiveness of LPD. Although there was no difference in overall morbidity in patients that underwent OPD or LPD during the learning curve, LPD during the learning curve was associated with a higher incidence of major complications. LOS was longer in patients that underwent LPD during the learning curve, which is not consistent with previous reports $(7,8,12,14,30)$. Further, the incidence of prolonged LOS $(>30 \mathrm{~d})$ was significantly increased in patients that underwent LPD during the learning curve. Multivariate analysis identified major surgery-associated complications as a significant predictor of prolonged LOS. Interestingly, we found LOS for patients with no or mild surgery-associated complications was significantly decreased in patients that underwent LPD during the learning curve, suggesting LPD during the learning curve may be effective in a carefully selected patient population.

The incidence of clinically relevant pancreatic fistula and bleeding that required invention were significantly increased in patients that underwent LPD during the learning curve compared to those that underwent OPD; however, there was no significant difference in the incidence of bleeding that required reoperation between groups. Age $>60$ years, LPD, and a non-dilated MPD were significant predictors of clinically relevant pancreatic fistula. Pancreatic texture has also been associated with pancreatic fistula (31-33), but this was not identified as a risk factor in the present study, possibly due to our small sample size. Pancreaticojejunostomy is a critical step in the LPD procedure, and skill in suturing techniques has an important influence on the incidence of pancreatic fistula. Suturing is technically challenging during laparoscopic surgery, as visibility is limited. Surgeons may lack advanced suturing techniques in the early phase of their learning curve for LPD, contributing to a high incidence of clinically relevant 
pancreatic fistula. Although there are many approaches to laparoscopic pancreaticojejunostomy (34-36), the optimal method remains to be elucidated.

In the present study, there was no significant difference in 90-day mortality in patients that underwent LPD during the learning curve or OPD. Age $>60$ years and a non-dilated MPD were significant predictors of postoperative 90-day mortality. Taken together, our data suggest that elderly patients and patients with a non-dilated MPD should not be treated by LPD performed by surgeons operating during their learning curves, especially in the early phase.

Consistent with previous studies $(7,12,13,30)$, the incidence of surgical site infection, times to resume outof-bed activities, bowel movements, and oral intake of a low-fat soft, solid diet, were significantly decreased in patients that underwent LPD during the learning curve compared to those that underwent OPD. These benefits are likely associated with the need for a smaller incision during laparoscopic surgery, which reduces postoperative pain. Further, intraoperative blood loss was significantly lower in patients that underwent LPD during the learning curve compared to those that underwent OPD, which is in accordance with other studies $(4,7,12,20)$. This may be related to magnification of visual scale during laparoscopic surgery, which allows visual enhancement of vascular structures.

Data from this study raise awareness of the need to ensure safety and improve the effectiveness of LPD during the learning curve, and provides guidance for centres introducing LPD to manage cancers of the pancreas. However, this study was associated with several limitations. First, there were limitations inherent to any retrospective non-randomized study. Although we used propensity score matching to minimize bias, there were still unknown confounders that might have affected outcomes. Second, our study was a single-center study, while previous research has been conducted at multiple sites (12); but our results are relevant for high-volume centers $(24,25)$.

\section{Conclusions}

Findings from this study showed that OT, incidence of major surgery-associated complications, and LOS were significantly increased in patients that underwent LPD during the learning curve compared to those that underwent OPD. These outcomes improved and approached those achieved with OPD in the later stages of the learning curve for LPD. We propose that elderly patients and patients with a non-dilated MPD should not be treated by LPD performed by inexperienced surgeons.

\section{Acknowledgments}

The authors thank all of the participating patients and their families, as well as the investigators, research nurses, study coordinators, and surgical staff.

Funding: This study was supported in part by a grant from the National Natural Science Foundation of China (\#81772560 to YW) and the Natural Science Foundation for Distinguished Young Scholars of Fujian Province (\#2018J06020 to SC).

\section{Footnote}

Reporting Checklist: The authors have completed the STROBE reporting checklist. Available at http://dx.doi. org/10.21037/gs-20-98

Data Sharing Statement: Available at http://dx.doi. org/10.21037/gs-20-98

Conflicts of Interest: All authors have completed the ICMJE uniform disclosure form (available at http://dx.doi. org/10.21037/gs-20-98). The authors have no conflicts of interest to declare.

Ethical Statement: The authors are accountable for all aspects of the work in ensuring that questions related to the accuracy or integrity of any part of the work are appropriately investigated and resolved. The study was conducted in accordance with the Declaration of Helsinki (as revised in 2013), and the protocol was approved by the institutional review board at Fujian provincial hospital (ID: K2019-04-002). And informed consent was taken from all the patients.

Open Access Statement: This is an Open Access article distributed in accordance with the Creative Commons Attribution-NonCommercial-NoDerivs 4.0 International License (CC BY-NC-ND 4.0), which permits the noncommercial replication and distribution of the article with the strict proviso that no changes or edits are made and the original work is properly cited (including links to both the formal publication through the relevant DOI and the license). 
See: https://creativecommons.org/licenses/by-nc-nd/4.0/.

\section{References}

1. Gagner M, Pomp A. Laparoscopic pylorus-preserving pancreatoduodenectomy. Surg Endosc 1994;8:408-10.

2. Nagakawa Y, Nakamura Y, Honda G, et al. Learning curve and surgical factors influencing the surgical outcomes during the initial experience with laparoscopic pancreaticoduodenectomy. J Hepatobiliary Pancreat Sci 2018;25:498-507.

3. Wang M, Meng L, Cai Y, et al. Learning Curve for Laparoscopic Pancreaticoduodenectomy: a CUSUM Analysis. J Gastrointest Surg 2016;20:924-35.

4. de Rooij T, Klompmaker S, Hilal MA, et al. Laparoscopic pancreatic surgery for benign and malignant disease. Nat Rev Gastroenterol Hepatol 2016;13:227-38.

5. Zhang $\mathrm{H}, \mathrm{Wu} \mathrm{X}, \mathrm{Zhu} \mathrm{F}$, et al. Systematic review and metaanalysis of minimally invasive versus open approach for pancreaticoduodenectomy. Surg Endosc 2016;30:5173-84.

6. Doula C, Kostakis ID, Damaskos C, et al. Comparison Between Minimally Invasive and Open Pancreaticoduodenectomy: A Systematic Review. Surg Laparosc Endosc Percutan Tech 2016;26:6-16.

7. Nassour I, Wang SC, Christie A, et al. Minimally Invasive Versus Open Pancreaticoduodenectomy: A Propensitymatched Study From a National Cohort of Patients. Ann Surg 2018;268:151-7.

8. Klompmaker S, van Hilst J, Wellner UF, et al. Outcomes After Minimally-invasive Versus Open Pancreatoduodenectomy: A Pan-European Propensity Score Matched Study. Ann Surg 2020;271:356-63.

9. Kayao lu HA, Cayci HM, Erdogdu UE, et al. Laparoscopic pancreaticoduodenectomy in pancreatic cancer: Our initial experience. Turk J Surg 2018;34:323-6.

10. Adam MA, Choudhury K, Dinan MA, et al. Minimally Invasive Versus Open Pancreaticoduodenectomy for Cancer: Practice Patterns and Short-term Outcomes Among 7061 Patients. Ann Surg 2015;262:372-7.

11. Cai Y, Luo H, Li Y, et al. A novel technique of pancreaticojejunostomy for laparoscopic pancreaticoduodenectomy. Surg Endosc 2019;33:1572-7.

12. Wang M, Peng B, Liu J, et al. Practice Patterns and Perioperative Outcomes of Laparoscopic Pancreaticoduodenectomy in China: A Retrospective Multicenter Analysis of 1029 Patients. Ann Surg 2019. [Epub ahead of print].

13. Tran TB, Dua MM, Worhunsky DJ, et al. The First
Decade of Laparoscopic Pancreaticoduodenectomy in the United States: Costs and Outcomes Using the Nationwide Inpatient Sample. Surg Endosc 2016;30:1778-83.

14. Stauffer JA, Coppola A, Villacreses D, et al. Laparoscopic versus open pancreaticoduodenectomy for pancreatic adenocarcinoma: long-term results at a single institution. Surg Endosc 2017;31:2233-41.

15. Pędziwiatr M, Małczak P, Pisarska M, et al. Minimally invasive versus open pancreatoduodenectomy-systematic review and meta-analysis. Langenbecks Arch Surg 2017;402:841-51.

16. Zhang H, Guo X, Xia J, et al. Comparison of Totally 3-Dimensional Laparoscopic Pancreaticoduodenectomy and Open Pancreaticoduodenectomy. Pancreas 2018;47:592-600.

17. Koch M, Garden OJ, Padbury R, et al. Bile leakage after hepatobiliary and pancreatic surgery: a definition and grading of severity by the International Study Group of Liver Surgery. Surgery 2011;149:680-8.

18. Bassi C, Marchegiani G, Dervenis C, et al. The 2016 update of the International Study Group (ISGPS) definition and grading of postoperative pancreatic fistula: 11 Years After. Surgery 2017;161:584-91.

19. Chen K, Pan Y, Liu X, et al. Minimally invasive pancreaticoduodenectomy for periampullary disease: a comprehensive review of literature and meta-analysis of outcomes compared with open surgery. BMC Gastroenterology 2017;17:120.

20. Poves I, Burdio F, Morato O, et al. Comparison of Perioperative Outcomes Between Laparoscopic and Open Approach for Pancreatoduodenectomy: The PADULAP Randomized Controlled Trial. Ann Surg 2018;268:731-9.

21. Bausch D, Keck T. Minimally Invasive Surgery of Pancreatic Cancer: Feasibility and Rationale. Visc Med 2018;34:440-3.

22. Dokmak S, Ftériche FS, Aussilhou B, et al. Laparoscopic pancreaticoduodenectomy should not be routine for resection of periampullary tumors. J Am Coll Surg 2015;220:831-8.

23. Sharpe SM, Talamonti MS, Wang CE, et al. Early National Experience with Laparoscopic Pancreaticoduodenectomy for Ductal Adenocarcinoma: A Comparison of Laparoscopic Pancreaticoduodenectomy and Open Pancreaticoduodenectomy from the National Cancer Data Base. J Am Coll Surg 2015;221:175-84.

24. Kutlu OC, Lee JE, Katz MH, et al. Open Pancreaticoduodenectomy Case Volume Predicts Outcome of Laparoscopic Approach: A Population-based Analysis. 
Ann Surg 2018;267:552-60.

25. Adam MA, Thomas S, Youngwirth L, et al. Defining a Hospital Volume Threshold for Minimally Invasive Pancreaticoduodenectomy in the United States. JAMA Surg 2017;152:336-42.

26. Strobel O, Büchler MW. Laparoscopic pancreatoduodenectomy: safety concerns and no benefits. Lancet Gastroenterol Hepatol 2019;4:186-7.

27. van Hilst J, de Rooij T, Bosscha K, et al. Laparoscopic versus open pancreatoduodenectomy for pancreatic or periampullary tumours (LEOPARD-2): a multicentre, patient-blinded, randomised controlled phase 2/3 trial. Lancet Gastroenterol Hepatol 2019;4:199-207.

28. Kim SC, Song KB, Jung YS, et al. Short-term clinical outcomes for 100 consecutive cases of laparoscopic pylorus-preserving pancreatoduodenectomy: improvement with surgical experience. Surg Endosc 2013;27:95-103.

29. Lee JW, Kim DH, Kim JI, et al. Laparoscopic pancreaticoduodenectomy: CUSUM analysis in a developing single surgeon. HPB Surgery Week 2019. Available online: http://www.kahbps.or.kr/upload/ conference_files/19_071/1914383967_1556090186.pdf

30. Conrad C, Basso V, Passot G, et al. Comparable longterm oncologic outcomes of laparoscopic versus open pancreaticoduodenectomy for adenocarcinoma: a propensity score weighting analysis. Surg Endosc

Cite this article as: Huang L, Tian Y, Wu J, Yan M, Qiu F, Zhou S, Bai Y, Lai Z, Wang Y, Chen S. The effectiveness, risks and improvement of laparoscopic pancreaticoduodenectomy during the learning curve: a propensity score-matched analysis. Gland Surg 2020;9(4):985-999. doi: 10.21037/gs-20-98
2017;31:3970-8.

31. Martin AN, Narayanan S, Turrentine FE, et al. Pancreatic duct size and gland texture are associated with pancreatic fistula after pancreaticoduodenectomy but not after distal pancreatectomy. PLoS One 2018;13:e0203841.

32. Yuan F, Essaji Y, Belley-Cote EP, et al. Postoperative complications in elderly patients following pancreaticoduodenectomy lead to increased postoperative mortality and costs. A retrospective cohort study. Int J Surg 2018;60:204-9.

33. McCracken EKE, Mureebe L, Blazer DG, 3rd. Minimally Invasive Surgical Site Infection in Procedure-Targeted ACS NSQIP Pancreaticoduodenectomies. J Surg Res 2019;233:183-91.

34. Wang $M, X u S$, Zhang $H$, et al. Imbedding pancreaticojejunostomy used in pure laparoscopic pancreaticoduodenectomy for nondilated pancreatic duct. Surg Endosc 2017;31:1986-92.

35. Karagul S, Kayaalp C, Sumer F, et al. Extramucosal pancreaticojejunostomy at laparoscopic pancreaticoduodenectomy. J Minim Access Surg 2018;14:76-8.

36. Lee YN, Kim WY. Comparison of Blumgart versus conventional duct-to-mucosa anastomosis for pancreaticojejunostomy after pancreaticoduodenectomy. Ann Hepatobiliary Pancreat Surg 2018;22:253-60. 